\title{
Effects of Vitamin A Status on Expression of Ucp1 and Brown/Beige Adipocyte- Related Genes in White Adipose Tissues of Beef Cattle
}

\author{
Yohei KANAMORI ${ }^{1) * *}$, Tomoya YAMADA ${ }^{2 * * *}$, Hiroki ASANO ${ }^{1)}$, Ryosuke KIDA ${ }^{1)}$, Yuhang QIAO $^{1)}$, \\ Mabrouk A. ABD ELDAIM ${ }^{1,3)}$, Shozo TOMONAGA ${ }^{1)}$, Tohru MATSUI ${ }^{1)}$ and Masayuki FUNABA ${ }^{1) *}$ \\ ${ }^{1)}$ Division of Applied Biosciences, Graduate School of Agriculture, Kyoto University, Kyoto 606-8502, Japan \\ ${ }^{2)}$ National Institute of Livestock and Grassland Science, Nasushiobara 329-2793, Japan \\ 3) Department of Biochemistry and Chemistry of Nutrition, Faculty of Veterinary Medicine, Sadat City University, Sadat City, 32897, \\ Egypt
}

(Received 15 March 2014/Accepted 7 May 2014/Published online in J-STAGE 23 May 2014)

ABSTRACT. We previously reported the presence of brown/beige adipocytes in the white fat depots of mature cattle. The present study examined the effects of dietary vitamin A on the expression of brown/beige adipocyte-related genes in the white fat depots of fattening cattle. No significant differences were observed in the expression of Ucp1 between vitamin A-deficient cattle and control cattle. However, the expression of the other brown/beige adipocyte-related genes was slightly higher in the mesenteric fat depots of vitamin A-deficient cattle. The present results suggest that a vitamin A deficiency does not markedly affect the expression of Ucp1 in white fat depots, but imply that it may stimulate the emergence of beige adipocytes in the mesenteric fat depots of fattening cattle.

KEY WORDS: beef cattle, beige adipocyte, brown adipocyte, Ucp1, vitamin A

doi: 10.1292/jvms.14-0137; J. Vet. Med. Sci. 76(9): 1261-1265, 2014

Brown adipocytes dissipate chemical energy in the form of heat against cold exposure or excess feeding [6]. The thermogenic function of brown adipocytes has been attributed to the expression of a series of genes related to a high mitochondrial content and elevation in cellular respiration that is largely uncoupled from ATP synthesis [6]. This uncoupling occurs through the expression of uncoupling protein 1 (Ucp1), a proton channel located at the inner mitochondrial membrane [9].

Beige adipocytes, also known as brite adipocytes, were originally called Ucp1-positive adipocytes and have been detected in murine white fat depots [25]; however, the molecular signatures of beige adipocytes were shown to differ from those of brown adipocytes in classical brown fat depots located at the interscapular region in mice $[23,24]$. Not only infants, but also adult humans possess Ucp1-positive adipocytes at the supraclavicular region and neck, and these have been identified as a mixture of brown and beige adipocytes based on their gene signatures $[8,23,24]$.

We recently detected brown/beige adipocytes in the white fat depots of fattening cattle [3]. The activation of brown/ beige adipocytes is preferable in adult humans, because of its potential usefulness in preventive or therapeutic procedures for obesity. However, this is not preferable in beef cattle,

*Correspondence to: Funaba, M., Division of Applied Biosciences, Graduate School of Agriculture, Kyoto University, Kitashirakawa Oiwakecho, Kyoto 606-8502, Japan.

e-mail: mfunaba@kais.kyoto-u.ac.jp

**These authors equally contributed to this study.

(C)2014 The Japanese Society of Veterinary Science

This is an open-access article distributed under the terms of the Creative Commons Attribution Non-Commercial No Derivatives (by-nc-nd) License $<$ http://creativecommons.org/licenses/by-nc-nd/3.0/>. because it decreases fattening efficiency, which is calculated as a ratio of body weight gain to feed intake. Feed ingredients have been shown to affect the activity of brown/beige adipocytes in beef cattle; the expression of Ucp1, which is frequently used as an index of the activation of brown/beige adipocytes [4, 14, 20, 21, 23, 24], was higher in the subcutaneous fat depots of cattle fed a high concentrate diet than those fed a high roughage diet [3]. To develop more efficient fattening programs for beef cattle, dietary factor (s) that affect the expression of Ucp1 and brown/beige adipocyteselective genes should be explored in more detail.

Retinoic acid, which is metabolized from the provitamin A $\beta$-carotene, is known to stimulate the transcription of murine Ucp1 [2]. Previous studies have demonstrated that the vitamin A status affects the expression of murine Ucp1 in classical brown fat depots; dietary supplementation with vitamin A increased the expression of Ucp $1[11,12]$, whereas a vitamin A deficiency suppressed it [5].

Although dietary vitamin $\mathrm{A}$ is frequently restricted in fattening beef cattle to improve beef marbling, the plasma concentration of retinol has to be maintained above $40 \mathrm{IU} /$ $\mathrm{d} l$ to prevent a severe vitamin A deficiency [16]. Yamada et al. [27] reported that the plasma concentration of retinol decreased with fattening in steers fed orchard grass hay and concentrate, reached approximately $20 \mathrm{IU} / \mathrm{d} l$ at 24 months of age and was thereafter maintained at approximately $40 \mathrm{IU} /$ $\mathrm{d} l$. In contrast, the concentration of retinol was maintained above $60 \mathrm{IU} / \mathrm{d} l$ in the plasma of steers fed a fermented total mixed ration (TMR) with more $\beta$-carotene during the fattening period [27]. Therefore, the expression of Ucp 1 may be lower in moderately vitamin A-deficient cattle fed orchard grass hay and concentrate than in fattening cattle fed the fermented TMR. The objective of this study was to clarify the effects of the vitamin A status in beef cattle during the 
A

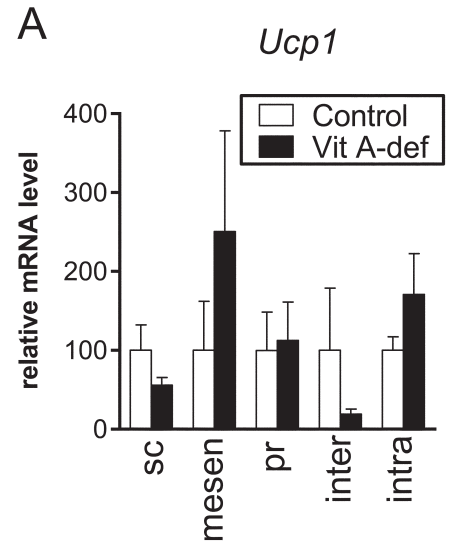

B

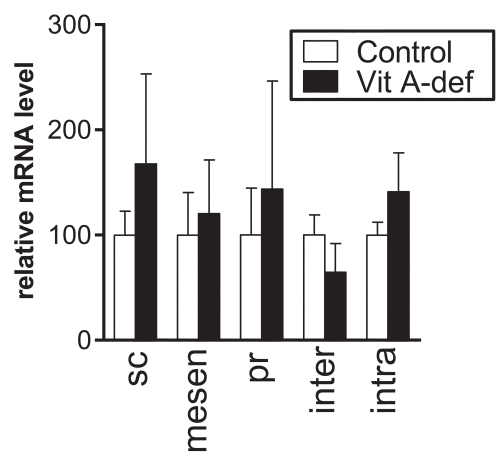

C

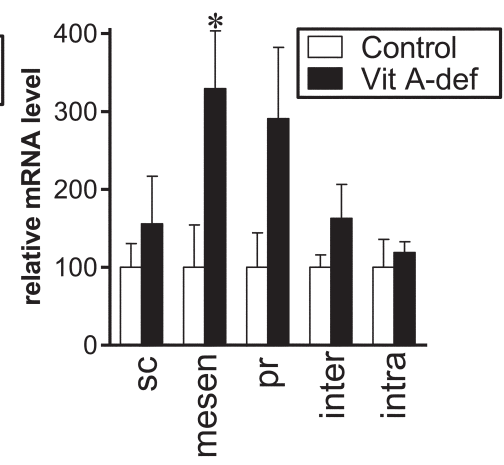

Fig. 1. Expression of Ucp1, Fabp4 and Prdm16 in the white fat depots of fattening cattle. Fattening cattle were fed either a control diet or vitamin A-deficient (Vit A-def) diet for 20 months. At 30 months of age, subcutaneous (sc), mesenteric (mesen), perirenal (pr), intermuscular (inter) and intramuscular (intra) WAT depots were collected, and the expression of Ucp1 (A), Fabp4 (B) and Prdm16 (C) was examined by RT-qPCR. Expression levels were normalized to Hprt1 expression, and expression levels in each WAT depot in the control group were set to 100 . Data are shown as the mean $\pm \mathrm{SE}(\mathrm{n}=4)$. $* P<0.05$.

fattening period.

Eight Japanese Black steers aged 10 months were used. They were fed hay and concentrate containing 5,000 IU/kg of vitamin A on an ad libitum basis before the experiment. The feeding experiment was the same as that reported by Yamada et al. [26, 27]. Data on daily feed intake, body composition and the plasma concentration of retinol were shown previously $[26,27]$. The steers were raised in a stall covered with sawdust. They were allowed free access to drinking water and a mineral block (Cowstone, Nihon Zenyaku Kogyo, Koriyama, Japan). Feeds were individually provided by a door feeding system (Orion Machinery, Kyoto, Japan). The steers were allotted by body weight to 1 of 2 groups: the control group $(n=4)$ or vitamin A-deficient group $(n=4)$. Two kinds of fermented TMR containing whole crop rice silage, fermented by-products (beer cake and tofu cake) and concentrate were prepared in a TMR center and fed to the steers in the control group. Total digestible nutrients (TDN), crude protein (CP) and $\beta$-carotene contents in the TMR for steers aged 10-20 months were $72 \%, 13 \%$ and $16 \mathrm{mg} / \mathrm{kg}$ as dry matter basis, respectively, and those for steers aged 21-30 months were $77 \%, 14 \%$ and $7 \mathrm{mg} / \mathrm{kg}$ as dry matter basis. The TMR was stored in under a sealed condition until feeding. The steers in the vitamin A-deficient group were fed roughage (orchard grass hay) with $56 \%$ TDN, $8 \% \mathrm{CP}$ and $0.5 \mathrm{mg} / \mathrm{kg} \beta$-carotene and a concentrate mixture consisting of corn, barley, wheat bran, rice bran and soybean meal (Nasuno for Wagyu Fattening; JA Higashi-nihon Kumiai Shiryou, Ota, Japan) with $88 \%$ TDN, $15 \%$ CP and $0.1 \mathrm{mg} / \mathrm{kg}$ $\beta$-carotene. The supplied dry matter amount of orchard grass hay in the vitamin A-deficient group was matched to that of whole crop rice silage in the control diet to equalize the ratio of roughage to concentrate between the 2 groups. To eliminate the influence of the total TDN intake between the groups, the steers were pair-fed for 20 months. The collection of fat depots was described previously [28]. All animals received humane care as outlined in the Guide for the Care and Use of Experimental Animals (National Institute of Livestock and Grassland Science).

Total RNA isolation and cDNA synthesis were conducted as described by Asano et al. [3]. cDNA, which was reversetranscribed from $10 \mathrm{ng}$ of total RNA, was used as a template for RT-quantitative PCR (RT-qPCR). The oligonucleotide primers for RT-qPCR have been described previously [3], except for Fabp4. The PCR primers for Fabp4 were 5'-ggtacaagtacaaaactgggatgg-3' and 5'-ccagcaccatcttatcatcca-3'. The $C_{t}$ value was determined, and the abundance of gene transcripts was calculated from the $\mathrm{C}_{\mathrm{t}}$ value by normalizing against Hprt1. Expression levels in each WAT depot in the control group were set to 100 .

Data are expressed as the mean $\pm \mathrm{SE}$. Data on gene expression were log-transformed to provide an approximation of a normal distribution before analyses. Differences between the control group and vitamin A-deficient group were examined using an unpaired $t$-test. Differences of $P<0.05$ were considered significant.

No significant differences were observed in the expression of Ucp 1 in all white fat depots between the control and vitamin A-deficient groups (Fig. 1A). The expression levels of Ucp1 in the mesenteric fat depots and intramuscular fat depots in the control group were numerically lower and higher, respectively, than those in the subcutaneous fat depots in the control group (data not shown); the higher expression in the intermuscular fat depots may be related to the presence of brown adipocytes interspersed between the muscle bundles of mice [1].

The feed given to animals may affect adipogenesis; a previous study reported that retinoic acid inhibited Ppar $\gamma-$ induced adipogenesis [15]. Thus, we examined the expression of Fabp4, a gene expressed in mature adipocytes [10]. The expression of Fabp4 was also unaffected by the feed (Fig. 1B), and expression levels were similar among fat de- 


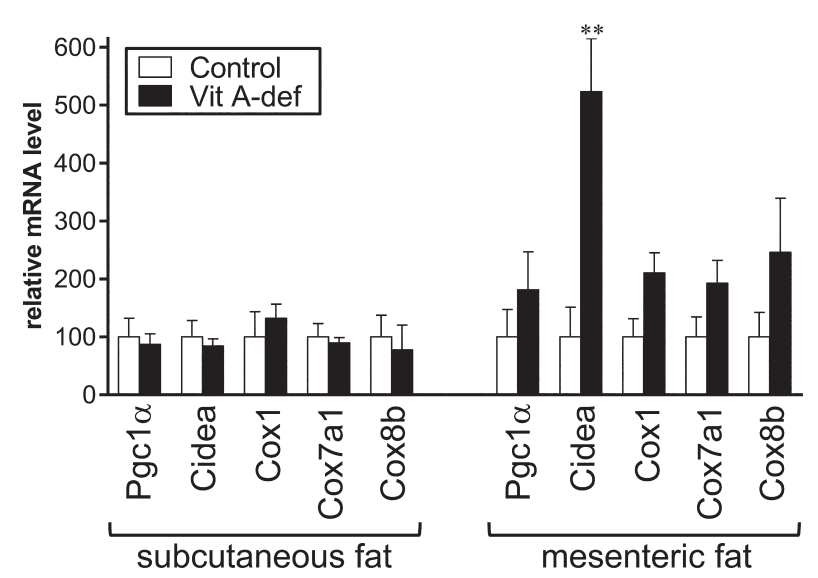

Fig. 2. Expression of brown/beige adipocyte-selective genes in the subcutaneous or mesenteric fat depots of fattening cattle. Fattening cattle were fed either a control diet or vitamin A-deficient (Vit Adef) diet for 20 months. The expression of brown/beige adipocyteselective genes in the subcutaneous WAT and mesenteric WAT was examined by RT-qPCR. Expression levels were normalized to Hprt1 expression, and expression levels in the control group were set to 100 . Data are shown as the mean $\pm \mathrm{SE}(\mathrm{n}=4) . * * P<0.01$.

pots in the control group (data not shown).

Prdm16 is a master regulator of the development of brown adipocytes as well as the emergence of beige adipocytes $[20,21]$ and is expressed in both stromal vascular cells including brown preadipocytes and brown adipocytes [21]. We found that the expression of Prdm 16 was significantly higher in the mesenteric fat depots of cattle fed vitamin A-deficient feed $(P=0.045$, Fig. $1 C)$.

The expression of Pgc-1 $\alpha$, Cidea, Cox1, Cox7a1 and Cox 8 b was previously shown to be higher in classical brown fat depots and white fat depots with more beige adipocytes than in white fat depots with less beige adipocytes [22-24]. No significant differences were observed in the expression of brown/beige adipocyte-selective genes in subcutaneous fat depots between the groups (Fig. 2). In contrast, the expression of Pgc-1 $\alpha$, Cidea, Cox1, Cox7a1 and Cox $8 b$ in mesenteric fat depots was generally higher in the vitamin Adeficient group than in the control group, with the expression of Cidea being significantly higher in the vitamin A-deficient group $(P=0.006)$. The expression of these brown/beige adipocyte-selective genes including Prdm16 was generally higher in the subcutaneous fat depots than in the mesenteric fat depots in the control group (data not shown).

The negative relationship between body mass index, an index of obesity, and the activity of brown/beige adipocytes [7] suggests that the activation of brown/beige adipocytes may contribute to the marked expenditure of energy in adult humans [17]. A previous study detected brown/beige adipocytes in mature cattle [3]; therefore, the activation of brown/beige adipocytes may have a deleterious effect on fattening efficiency. Our previous study revealed changes in the expression of Ucp 1 and brown/beige adipocyte-selective genes with diet in fattening cattle [3]. The present study demonstrated that the vitamin A-deficient diet did not affect the expression of Ucp 1 in the fat depots examined; however, the expression of the brown/beige adipocyte-selective genes was generally higher in the mesenteric fat depots of vitamin A-deficient cattle. Furthermore, the expression of Prdm16, a master regulator of brown/beige adipocyte development [20, 21], was significantly higher in the mesenteric fat depots of cattle fed the vitamin A-deficient diet; the reason why the expression of Prdm16 was up-regulated in vitamin A-deficient cattle currently remains unclear; therefore, future studies are needed to clarify the factors affecting the expression of Prdm16. The basal expression of Ucp 1 in beige adipocytes, but not brown adipocytes was shown to be as low as that in white adipocytes, but was enhanced in response to the activation of $\beta$ adrenergic receptors [24]. Thus, the present results imply that a vitamin A deficiency may stimulate the emergence of beige adipocytes in the mesenteric fat depots of fattening cattle.

In the present study, the expression of brown/beige adipocyte-selective genes, including $\operatorname{Prdm} 16$, in the mesenteric fat depots was generally higher in vitamin A-deficient cattle than in the control cattle, whereas no significant differences were observed in the subcutaneous fat depots between the groups. These results were in contrast to our previous findings [3]. In our previous study [3], the expression of brown/beige adipocyte-selective genes in the subcutaneous fat depots, but not in the mesenteric fat depots was higher in cattle fed the high concentrate diet than in those fed the high roughage diet; the protein/energy content of the high concentrate diet is higher than that of the high roughage diet. These results suggest that fat depots, in which potential brown/beige adipocytes emerge, vary depending on the manipulated nutrients.

We expected the expression of Ucp 1 to be down-regulated in fattening cattle fed the vitamin A-deficient diet based on the retinoic acid-induced transcription of murine Ucp1 [2]. However, the vitamin A deficiency did not affect the expression of Ucp1, and the precise reason for this is currently unknown. A species-dependent effect of retinoic acid-mediated Ucp1 expression has been reported previously; retinoic acid up-regulated the expression of Ucp1 in murine adipocytes, but not in human adipocytes $[2,13,18]$. Three possible retinoic acid-response elements, spanning nt -2490 to $n t-2399$ of rat Ucp1, have been identified based on the results on footprint assays and transcriptional activation assays; $\mathrm{nt}+1$ has been defined as a translational initiation site. The critical nucleotides within the elements, which were verified by reporter assays using the point-mutated promoter of rat Ucp1 [18], are mostly conserved in mouse Ucp1 (21 nucleotides within 22 nucleotides in mouse Ucp1 matched those of rat Ucp1). However, the corresponding nucleotides are less conserved in bovine Ucp1 (14/22) and human Ucp1 (17/22). The transcription of bovine Ucp1 may not be regulated by the vitamin A status.

Alternatively, the regulation of Ucp1 expression in a manner dependent on the location of fat depots may be related to the insensitivity of Ucp1 expression in fattening cattle fed a vitamin A-deficient diet. Schulz et al. [19] revealed the regulation of beige adipocyte activity by brown 
adipocyte activity; inhibition of brown adipocyte activation stimulated energy expenditure in beige adipocytes. Feeding fattening cattle a vitamin A-deficient diet may regulate the activity of brown and beige adipocytes differently, although the presence of classical brown fat depots has not yet been determined.

ACKNOWLEDGMENT. This work was supported by a Grant-in-Aid for Scientific Research (23580368) from The Japan Society for the Promotion of Science.

\section{REFERENCES}

1. Almind, K., Manieri, M., Sivitz, W. I., Cinti, S. and Kahn, C. R. 2007. Ectopic brown adipose tissue in muscle provides a mechanism for differences in risk of metabolic syndrome in mice. Proc. Natl. Acad. Sci. U.S.A. 104: 2366-2371. [Medline] [CrossRef]

2. Alvarez, R., de Andrés, J., Yubero, P., Viñas, O., Mampel, T., Iglesias, R., Giralt, M. and Villarroya, F. 1995. A novel regulatory pathway of brown fat thermogenesis. Retinoic acid is a transcriptional activator of the mitochondrial uncoupling protein gene. J. Biol. Chem. 270: 5666-5673. [Medline] [CrossRef]

3. Asano, H., Yamada, T., Hashimoto, O., Umemoto, T., Sato, R., Ohwatari, S., Kanamori, Y., Terachi, T., Funaba, M. and Matsui, T. 2013. Diet-induced changes in Ucp1 expression in bovine adipose tissues. Gen. Comp. Endocrinol. 184: 87-92. [Medline] [CrossRef]

4. Barbatelli, G., Murano, I., Madsen, L., Hao, Q., Jimenez, M., Kristiansen, K., Giacobino, J. P., De Matteis, R. and Cinti, S. 2010. The emergence of cold-induced brown adipocytes in mouse white fat depots is determined predominantly by white to brown adipocyte transdifferentiation. Am. J. Physiol. Endocrinol. Metab. 298: E1244-E1253. [Medline] [CrossRef]

5. Bonet, M. L., Oliver, J., Picó, C., Felipe, F., Ribot, J., Cinti, S. and Palou, A. 2000. Opposite effects of feeding a vitamin Adeficient diet and retinoic acid treatment on brown adipose tissue uncoupling protein 1 (UCP1), UCP2 and leptin expression. $J$. Endocrinol. 166: 511-517. [Medline] [CrossRef]

6. Cannon, B. and Nedergaard, J. 2004. Brown adipose tissue: function and physiological significance. Physiol. Rev. 84: 277-359. [Medline] [CrossRef]

7. Cypess, A. M., Lehman, S., Williams, G., Tal, I., Rodman, D., Goldfine, A. B., Kuo, F. C., Palmer, E. L., Tseng, Y. H., Doria, A., Kolodny, G. M. and Kahn, C. R. 2009. Identification and importance of brown adipose tissue in adult humans. N. Engl. J. Med. 360: 1509-1517. [Medline] [CrossRef]

8. Cypess, A. M., White, A. P., Vernochet, C., Schulz, T. J., Xue, R., Sass, C. A., Huang, T. L., Roberts-Toler, C., Weiner, L. S., Sze, C., Chacko, A. T., Deschamps, L. N., Herder, L. M., Truchan, N., Glasgow, A. L., Holman, A. R., Gavrila, A., Hasselgren, P. O., Mori, M. A., Molla, M. and Tseng, Y. H. 2013. Anatomical localization, gene expression profiling and functional characterization of adult human neck brown fat. Nat. Med. 19: 635-639. [Medline] [CrossRef]

9. Gesta, S., Tseng, Y. H. and Kahn, C. R. 2007. Developmental origin of fat: tracking obesity to its source. Cell 131: 242-256. [Medline] [CrossRef]

10. Hunt, C. R., Ro, J. H., Dobson, D. E., Min, H. Y. and Spiegelman, B. M. 1986. Adipocyte P2 gene: developmental expression and homology of 5 '-flanking sequences among fat cell-specific genes. Proc. Natl. Acad. Sci. U.S.A. 83: 3786-3790. [Medline]
[CrossRef]

11. Jeyakumar, S. M., Vajreswari, A. and Giridharan, N. V. 2006. Chronic dietary vitamin A supplementation regulates obesity in an obese mutant WNIN/Ob rat model. Obesity (Silver Spring) 14: 52-59. [Medline] [CrossRef]

12. Kumar, M. V., Sunvold, G. D. and Scarpace, P. J. 1999. Dietary vitamin A supplementation in rats: suppression of leptin and induction of UCP1 mRNA. J. Lipid Res. 40: 824-829. [Medline]

13. Murholm, M., Isidor, M. S., Basse, A. L., Winther, S., Sørensen, C., Skovgaard-Petersen, J., Nielsen, M. M., Hansen, A. S., Quistorff, B. and Hansen, J. B. 2013. Retinoic acid has different effects on UCP1 expression in mouse and human adipocytes. BMC Cell Biol. 14: 41. [Medline] [CrossRef]

14. Ohno, H., Shinoda, K., Spiegelman, B. M. and Kajimura, S. 2012. PPAR $\gamma$ agonists induce a white-to-brown fat conversion through stabilization of PRDM16 protein. Cell Metab. 15: 395-404. [Medline] [CrossRef]

15. Ohyama, M., Matsuda, K., Torii, S., Matsui, T., Yano, H., Kawada, T. and Ishihara, T. 1998. The interaction between vitamin $\mathrm{A}$ and thiazolidinedione on bovine adipocyte differentiation in primary culture. J. Anim. Sci. 76: 61-65. [Medline]

16. Oka, A. 1996. Effects of vitamin A on beef quality and body weight of Japanese Black steers (in Japanese). J. Anim. Genet. 24: 31-36. [CrossRef]

17. Ouellet, V., Labbé, S. M., Blondin, D. P., Phoenix, S., Guérin, B., Haman, F., Turcotte, E. E., Richard, D. and Carpentier, A. C. 2012. Brown adipose tissue oxidative metabolism contributes to energy expenditure during acute cold exposure in humans. $J$. Clin. Invest. 122: 545-552. [Medline] [CrossRef]

18. Rabelo, R., Reyes, C., Schifman, A. and Silva, J. E. 1996. A complex retinoic acid response element in the uncoupling protein gene defines a novel role for retinoids in thermogenesis. Endocrinology 137: 3488-3496. [Medline]

19. Schulz, T. J., Huang, P., Huang, T. L., Xue, R., McDougall, L. E., Townsend, K. L., Cypess, A. M., Mishina, Y., Gussoni, E. and Tseng, Y. H. 2013. Brown-fat paucity due to impaired BMP signalling induces compensatory browning of white fat. Nature 495: 379-383. [Medline] [CrossRef]

20. Seale, P., Bjork, B., Yang, W., Kajimura, S., Chin, S., Kuang, S., Scimè, A., Devarakonda, S., Conroe, H. M., ErdjumentBromage, H., Tempst, P., Rudnicki, M. A., Beier, D. R. and Spiegelman, B. M. 2008. PRDM16 controls a brown fat/skeletal muscle switch. Nature 454: 961-967. [Medline] [CrossRef]

21. Seale, P., Conroe, H. M., Estall, J., Kajimura, S., Frontini, A., Ishibashi, J., Cohen, P., Cinti, S. and Spiegelman, B. M. 2011. Prdm16 determines the thermogenic program of subcutaneous white adipose tissue in mice. J. Clin. Invest. 121: 96-105. [Medline] [CrossRef]

22. Seale, P., Kajimura, S., Yang, W., Chin, S., Rohas, L. M., Uldry, M., Tavernier, G., Langin, D. and Spiegelman, B. M. 2007. Transcriptional control of brown fat determination by PRDM16. Cell Metab. 6: 38-54. [Medline] [CrossRef]

23. Sharp, L. Z., Shinoda, K., Ohno, H., Scheel, D. W., Tomoda, E., Ruiz, L., Hu, H., Wang, L., Pavlova, Z., Gilsanz, V. and Kajimura, S. 2012. Human BAT possesses molecular signatures that resemble beige/brite cells. PLoS ONE 7: e49452. [Medline] [CrossRef]

24. Wu, J., Boström, P., Sparks, L. M., Ye, L., Choi, J. H., Giang, A. H., Khandekar, M., Virtanen, K. A., Nuutila, P., Schaart, G., Huang, K., Tu, H., van Marken Lichtenbelt, W. D., Hoeks, J., Enerbäck, S., Schrauwen, P. and Spiegelman, B. M. 2012. Beige adipocytes are a distinct type of thermogenic fat cell in mouse and human. Cell 150: 366-376. [Medline] [CrossRef] 
25. Wu, J., Cohen, P. and Spiegelman, B. M. 2013. Adaptive thermogenesis in adipocytes: is beige the new brown? Genes Dev. 27: 234-250. [Medline] [CrossRef]

26. Yamada, T., Higuchi, M. and Nakanishi, N. 2012. Effects of fermented TMR containing whole crop rice silage on carcass traits and lipid stability of meat in Japanese black steers Bull. Beef Cattle Sci. 92: 4-9 (in Japanese).

27. Yamada, T., Higuchi, M. and Nakanishi, N. 2013. Plasma 8-iso- prostane concentrations and adipogenic and adipokine gene expression patterns in subcutaneous and mesenteric adipose tissues of fattening Wagyu cattle. J. Vet. Med. Sci. 75: 1021-1027. [Medline] [CrossRef]

28. Yamada, T. and Nakanishi, N. 2012. Effects of the roughage/ concentrate ratio on the expression of angiogenic growth factors in adipose tissue of fattening Wagyu steers. Meat Sci. 90: 807-813. [Medline] 